\title{
PENGARUH PENYULUHAN TERHADAP PETERNAK BABI DI KECAMATAN KAWANGKOAN
}

\author{
Alma Rompas, A. A. Sajow*, S. O. B Lombogia, Z. M. Warouw \\ Fakultas Peternakan Universitas Sam Ratulangi Manado, 95115
}

\begin{abstract}
ABSTRAK
Penelitian ini dilaksanakan di Kecamatan Kawangkoan pada bulan Maret 2020. Penelitian ini bertujuan untuk mengetahui pengaruh penyuluhan terhadap peternak babi di Kecamatan Kawangkoan. Penelitian ini berbentuk survei dengan menggunakan kuesioner. Penentuan sampel dilakukan secara Purposive Sampling dengan jumlah responden 40 peternak babi. Analisis data yang digunakan pada penelitian ini adalah Analisis Chi-Square. Pengaruh penyuluhan diukur dengan menggunakan skala ordinal dari pertanyaan yang diajukan sedangkan pengetahuan, sikap dan keterampilan peternak babi di ukur menggunakan skala ordinal. Selanjutnya dengan menggunakan skoring terhadap jawaban responden terhadap pertanyaan ataupun pernyataan yang diberikan diperoleh beberapa kategori dari ketiga variabel tersebut. Variabel pengetahuan kategorinya pengetahuan tinggi, sedang dan rendah., sikap kategorinya menerima, cukup menerima dan kurang menerima, keterampilan kategorinya terampil, cukup terampil dan kurang terampil . Hasil Penelitian dengan menggunakan Analisis Chi-Square menunjukkan bahwa penyuluhan memberikan pengaruh terhadap pengetahuan, sikap dan keterampilan peternak babi.
\end{abstract}

Kata Kunci : Penyuluhan, Perilaku peternak, Analisis Chi-Square.

*Korespondensi (corresponding author):

Email: adriesajow@unsrat.ac.id

\section{ABSTRACT}

\section{THE EXTENSION EFFECT ON PIG} FARMERS IN KAWANGKOAN DISTRICT. This research was conducted in Kawangkoan District in March 2020. This study aimed to determine the effect of extension on pig farmers in Kawangkoan District. This research was conducted by a survey method using a questionnaire. Sample was determined by Purposive toward 40 pig farmers. Analysis of the data used in this study was the Chi-Square analysis. The variable of extension, knowledge, attitudes and skills of pig farmers was measured using an ordinal scale. Then by scoring respondents' answers or statements given, several categories of the three variables were obtained. The categorical knowledge variable was increased knowledge, quite increasing and not increasing. The results of the study using Chi-Square Analysis showed that counseling had an influence on the knowledge, attitudes and skills of pig farmers.

Keywords: Effect of counseling, Behavior of farmers, Chi-Square Analysis. 


\section{PENDAHULUAN}

Ternak babi di Indonesia telah cukup lama diketahui masyarakat, namun pengetahuan tentang beternak babi yang benar dan produktif belum banyak diterapkan, mengingat kurangnya informasi akibatnya peternakan babi di Indonesia cenderung masih dilakukan secara tradisional bahkan masih banyak peternakan babi yang dikelola secara sangat sederhana. Asngari (2001) menyatakan bahwa, untuk mengubah perilaku seseorang, dapat dilakukan dengan mengubah salah satu unsur perilaku atau ketiga-tiganya, yaitu: pengetahuan, sikap dan keterampilan Salah satu kegiatan yang dapat menumbuh kembangkan peternak menjadi peternak yang berkualitas adalah dengan adanya kegiatan penyuluhan. Penyuluhan adalah salah satu kegiatan yang dapat memberikan dampak positif bagi peternak itu sendiri, baik pengetahuan tentang cara beternak babi maupun hal-hal lain yang berkaitan dengan usaha ternak babi. Penyuluhan peternakan adalah pemberdayaan peternak dan keluarganya beserta masyarakat pelaku agribisnis melalui kegiatan pendidikan non formal dibidang peternakan agar mereka mampu menolong dirinya sendiri baik dibidang ekonomi, sosial maupun politik sehingga peningkatan pendapatan dan kesejahteraan mereka dapat dicapai (Tulong at al., 2019). Priyono et al. (2015), menyatakan bahwa kontribusi tingkat teknologi, dukungan kelembagaan, dan peran penyuluhan secara simultan memiliki pengaruh nyata terhadap tingkat adopsi oleh peternak. Hasil dari penyuluhan tidak dapat diketahui dalam waktu yang singkat terlebih lagi jika tujuan utama suatu program penyuluhan adalah terjadinya adopsi suatu inovasi yang ditawarkan atau terjadinya perubahan perilaku sasaran tentu akan membutuhkan waktu yang relatif lama (Gobel et al., 2018). Permasalahan dilapangan yang berkaitan dengan kegiatan penyuluhan ialah masih kurangnya pengetahuan, sikap, keterampilan peternak dalam keberhasilan beternak. Dengan kegiatan penyuluhan diharapkan dapat memberikan dampak positif dalam hal pengembangan usaha peternakan babi. Penyuluhan bertujuan untuk mengubah perilaku yaitu sikap, pengetahuan dan keterampilan petani (Yulida et al., 2012). Pada hakekatnya, berbicara tentang penyuluhan setidaknya menyangkut lima unsur yaitu: proses pembelajaran, ada subyek yang belajar, pengembangan kesadaran dan kapasitas diri, dan kelompok pengelolaan sumberdaya untuk perbaikan kehidupan, 
dan diterapkannya prinsip berkelanjutan dari sisi sosial, ekonomi, serta menerapkan fungsi kelestarian lingkungan (Amanah, 2007). Jika kegiatan penyuluhan kurang baik, maka perlu adanya peningkatan kinerja dari penyuluh, sebaliknya jika kegiatan penyuluhan sudah baik maka penyuluh sudah menjalankan tugas dengan baik. Penyuluhan adalah salah satu kegitan yang dapat menunjang penciptaan pemberdayaan pada masyarakat tani ternak (Ediset et al., 2013). Penyuluhan yang dilaksanakan dikatakan meningkat apabila terjadi perubahan pengetahuan, sikap dan keterampilan dari peternak dalam mengadopsi teknologi untuk meningkatkan cara beternak agar lebih baik. Rintjap et al. (2017) mengatakan bahwa kegiatan penyuluhan adalah menciptakan perubahan termasuk di dalamnya pengetahuan, sikap dan keterampilan. Ratnada dan Yusuf (2003) menyimpulkan bahwa, faktor-faktor yang berpengaruh pada perilaku petani adalah motivasi petani mencapai keberhasilan, wawasan petani, keaktifan petani mencari informasi dan intensitas penyuluhan.

Tujuan penelitian ini, untuk menganalisis pengaruh penyuluhan terhadappeternak babi di Kelurahan Sendangan Selatan, Sendangan dan Desa
Tondegesan , Tondegesan II Kecamatan Kawangkoan.

\section{METODE PENELITIAN}

\section{Waktu dan Tempat Penelitian}

Penelitian ini dilaksanakan di Kecamatan Kawangkoan Kelurahan Sendangan, Sendangan Selatan Desa Tondegesan, Tondegesan II pada bulan maret 2020 .

\section{Jenis dan Sumber Data}

Penelitian ini berbentuk survey dan merupakan jenis penelitian kualitatif yaitu penelitian yang bersifat menjelaskan bagaimana pengaruh penyuluhan terhadap pengetahuan, sikap dan keteramnpilan peternak babi. Sumber data dalam penelitian ini adalah data primer dan data sekunder. Data primer yaitu data yang diperoleh dari observasi wawancara langsung dan juga melalui bantuan daftar pertanyaan yang diberikan kepada peternak babi yang ada di Kelurahan Sendangan, Sendangan Selatan dan Desa Tondegesan, Tondegesan II, sedangkan data sekunder adalah data yang diperoleh dari instansi pemerintah baik dari Kelurahan Sendangan, Sendangan Selatan dan Desa Tondegesan, Tondegesan II, maupun dari BPP Kecamatan Kawangkoan.

\section{Metode Penentuan Sampel}


Lokasi penelitian diambil secara purposive sampling dengan pertimbangan terdapat peternak babi dan mempunyai jumlah ternak babi terbanyak. Populasi adalah peternak babi yang berada di Kecamatan Kawangkoan. Penentuan sampel peternak menggunakan metode purposive sampling, dengan pertimbangan peternak memiliki minimal 10 ekor ternak babi dewasa, beternak minimal 2 tahun dan peternak pernah mengikuti kegiatan penyuluhan minimal 4 kali dalm setahun. Jumlah sampel di empat desa/kelurahan terpilih adalah 10 peternak sehigga jumlah keseluruhan sampel peternak dalam penelitian ini yaitu 40 peternak. Menurut Tsalitsa et al. (2016), purposive sampling yaitu pengambilan sampel dari populasi berdasarkan kriteria tertentu.

\section{Analisis Data}

Analisis data yang digunakan dalam penelitian ini adalah metode deskriptif, yaitu suatu metode atau cara menganalisis dan menguraikan data penelitian yang ada, dan dikaitkan dengan teori-teori yang ada. Penyuluhan di ukur dengan skala ordinal dari pertanyaan yang di ajukan dan pengetahuan, sikap dan keterampilan peternak babi menggunakan skala ordinal. Selanjutnya dengan menggunakan skoring terhadap jawaban responden maka variabel penyuluhan terdiri dari kategori efektif, cukup efektif, tidak efektif pengetahuan terdiri atas pengetahuan tinggi, sedang dan rendah, variabel sikap terdiri atas menerima, cukup menerima dan kurang menerima, variabel keterampilan terdiri atas kategori terampil, cukup terampil dan cukup terampil .Untuk menguji variabel pengaruh penyuluhan terhadap peternak babi menggunakan analisis metode Chi Square $\left(\chi^{2}\right)$ adalah pengujian hipotesis mengenai perbandingan antara frekuensi observasi atau yang benar benar terjadi $\left(O_{i}\right)$ dengan frekuensi harapan atau ekspetasi $\left(e_{i}\right)$ yang di dasarkan atas hipotesis tertentu. Frekuensi observasi nilainya didapat dari hasil percobaan, sedangkan frekuensi harapan nilainya dapat di hitung secara teoritis,

Rumus :

$$
\chi^{2}=\sum \frac{\left(o_{i}-e_{i}\right)^{2}}{\varepsilon_{i}}
$$

Dimana :

$\chi^{2}=$ Variabel

$O_{i}=$ Frekuensi data yang didapat dari hasil observasi

$e_{i}=$ Frekuensi data harapan atau data yang diharapkan.

\section{HASIL DAN PEMBAHASAN}

\section{Penyuluhan}

Penyuluhan diukur dengan menghitung hasil jawaban dari peternak berdasarkan pertanyaan. Penyuluhan, 
merupakan aktivitas dari suatu kegiatan proses pembelajaran, maka keberhasilannya akan sangat bergantung pula kepada sejauh mana proses pembelajaran tersebut dapat berlangsung dengan sebaik-baiknya. Hasil penelitian pada Tabel 1 menunjukkan bahwa pengaruh penyuluhan efektif dengan presentase $75 \%$, cukup efektif $12.5 \%$ dan tidak efektif $12.5 \%$, artinya bahwa penyuluhan memberikan pengaruh terhadap peternak babi dalam menjalankan kegiatan usaha peternakaanya.

\section{Pengetahuan Peternak Babi}

Pengetahuan sangat diperlukan oleh seseorang peternak babi untuk melihat adanya perubahan atau tidak dalam mengikuti kegiatan penyuluhan. Pada Tabel 2 menunjukkan bahwa pengaruh penyuluhan dalam hal untuk meningkatkan pengetahuan peternak dalam menjalankan usahanya ditinjau dari beberapa parameter pertanyaan yaitu dari jenis ternk babi yang di pelihara, cara mengawinkan ternak babi, bibit berkualitas dinilai sudah baik.

\section{Sikap Peternak}

Sikap dalam hal ini mengacu pada mampunya peternak merespon setiap inovasi yang diberikan penyuluh untuk peternak agar mampu menjalankannya usaha peternakan babi dengan baik. Hasil penelitian pada Tabel 3 menunjukkan penyuluhan memberikan pengaruh yang baik kepada peternak babi dalam merubah sikap peternak babi dan hasilnya menunjukkan bahwa sikap peternak babi setelah adanya penyuluhan mengalami peningkatan. Artinya setelah ada kegiatan penyuluhan peternak dapat merespon inovasi - inovasi dari penyuluh.

\section{Keterampilan Peternak}

Keterampilan dalam hal ini sangat diperlukan untuk melihat apakah seorang peternak mampu menjadi terampil dalam usaha peternakannya Tabel 4 menunjukkan bahwa peternak babi dalam hal keterampilan dinilai sudah baik. Dari hasil penelitian dapat dilihat bahwa peternak sudah mampu menjalankan dengan terampil dalam hal ini peternak sudah tahu cara pencegahan penyakit, jumlah pemberian pemberian pakan pada ternak babi.

\section{Uji Chi Square Pengaruh Penyuluhan Terhadap Peternak Babi}

Untuk melihat adanya pengaruh penyuluhan terhadap peternak babi di Kelurahan Sendangan Selatan, Sendangan, Tondegesan dan Tondegesan II, maka dilakukan Uji Chi Square Pengaruh penyuluhan terhadap peternak babi (Tabel 5 dan 6)) 
Tabel 1. Penyuluhan

\begin{tabular}{llll}
\hline No & Penyuluhan & Jumlah (orang) & Presentase (\%) \\
\hline 1. & Efektif & 30 & 75 \\
2. & Cukup Efektif & 5 & 12.5 \\
3. & Tidak Efektif & 5 & 12.5 \\
& Jumlah & 40 & 100 \\
\hline
\end{tabular}

Tabel 2. Pengetahuan Peternak

\begin{tabular}{llll}
\hline No & Pengetahuan & Jumlah (orang) & Presentase $(\%)$ \\
\hline 1. & Pengetahuan Tinggi & 28 & 70 \\
2. & Pengetahuan Sedang & 7 & 17.5 \\
3. & Pengetahuan Rendah & 5 & 12.5 \\
& Jumlah & 40 & 100 \\
\hline
\end{tabular}

Tabel 3. Sikap Peternak

\begin{tabular}{llll}
\hline No & Sikap & Jumlah (orang) & Presentase (\%) \\
\hline 1. & Menerima Inovasi & 29 & 72.5 \\
2. & Cukup Menerima & 6 & 15 \\
3. & Tidak Menerima & 5 & 12.5 \\
& Jumlah & 40 & 100 \\
\hline
\end{tabular}

Tabel 4. Keterampilan Peternak

\begin{tabular}{llll}
\hline No & Keterampilan & Jumlah (orang) & Presentase (\%) \\
\hline 1. & Terampil & 28 & 70 \\
2. & Cukup Terampil & 7 & 17.5 \\
3. & Tidak Terampil & 5 & 12.5 \\
& Jumlah & 40 & 100 \\
\hline
\end{tabular}

Tabel 5. Nilai Kontingensi Pengaruh Penyuluhan Pada Pengetahuan Peternak Babi.

\begin{tabular}{|c|c|c|c|c|c|c|c|}
\hline \multirow{3}{*}{ Penyuluhan } & \multicolumn{6}{|c|}{ Pengetahuan Peternak } & \multirow{3}{*}{$\begin{array}{l}\text { Total } \\
\text { Baris }\end{array}$} \\
\hline & \multicolumn{2}{|c|}{ Tinggi } & \multicolumn{2}{|c|}{ Sedang } & \multicolumn{2}{|c|}{ Rendah } & \\
\hline & $\left(o_{i}\right)$ & $\left(e_{i}\right)$ & $\left(o_{i}\right)$ & $\left(e_{i}\right)$ & $\left(o_{i}\right)$ & $\left(e_{i}\right)$ & \\
\hline Efektif & 25 & 21.00 & 3 & 5.25 & 2 & 3.75 & 30 \\
\hline Cukup Efektif & 2 & 4.9 & 3 & 1.22 & 2 & 0.87 & 7 \\
\hline Kurang Efektif & 1 & 2.1 & 1 & 0.52 & 1 & 0.37 & 3 \\
\hline Total Kolom & 28 & & 7 & & 5 & & 40 \\
\hline
\end{tabular}


Tabel 6. Uji Analisis Chi Square Pengaruh Penyuluhan Terhadap Pengetahuan Peternak

\begin{tabular}{lccccc}
$\begin{array}{l}\text { Penyuluhan/ } \\
\text { Pengetahuan }\end{array}$ & $o_{i}$ & $e_{i}$ & $\left(o_{i}-e_{i}\right)$ & $\left(o_{i}-e_{i}\right)^{2}$ & $\begin{array}{c}\left(o_{i}-e_{i}\right)^{2} / \\
e_{i}\end{array}$ \\
\hline (E) Pengetahuan Tinggi & 25 & 21 & 4 & 0.40 & 0.0190 \\
(E) Pengetahuan Sedang & 3 & 5.25 & -2.25 & 5.06 & 0.9642 \\
(E) Pengetahuan Rendah & 2 & 3.75 & -1.75 & 3.06 & 0.8166 \\
(CE) Pengetahuan Tinggi & 2 & 4.9 & -2.9 & 8.41 & 1.7163 \\
(CE) Pengetahuan Sedang & 3 & 1.22 & 1.78 & 3.16 & 2.5970 \\
(CE) Pengetahuan Rendah & 2 & 0.87 & 1.13 & 1.27 & 1.4677 \\
(TE) Pengetahuan Tinggi & 1 & 2.1 & -1.1 & 1.21 & 0.5761 \\
(TE) Pengetahuan Sedang & 1 & 0.52 & 0.48 & 0.23 & 0.4430 \\
(TE) Pengetahuan Rendah & 1 & 0.37 & 0.63 & 0.39 & 1.0727 \\
\hline Jumlah & 40 & & & & 9.6726 \\
\hline
\end{tabular}

Keterangan :

(E) : Efektif

(CE) : Cukup Efektif

(TE) : Tidak Efektif

Untuk mengetahui pengaruh penyuluhan terhadap pengetahuan maka dilakukan pengujian kebebasan variabel dengan taraf uji $5 \%$.

Ukuran tabel kontingensi (Tabel 5) adalah matriks $3 \times 3$ (3 baris dan 3 kolom) $\mathrm{db}=(3-1)(3-1)=2 \times 2=4$; nilai

Tabel $x^{2} \mathrm{db}=4 ; \alpha=0.05$;

$x^{2}$ tabel $=9.488 ; x^{2}$ hitung $=9.6726$

$x^{2}$ tabel $=9.488$;

$x^{2}$ hitung lebih besar dari $x^{2}$ tabel, artinya penyuluhan memberikan pengaruh nyata terhadap pengetahuan peternak babi.. Anisa, et al., (2016) menyatakan bahwa pengetahuan merupakan tingkatan keseluruhan pemikiran gagasan ide dan konsep.

Tabel 7. Nilai Kontingensi Pengaruh Penyuluhan Pada Sikap Peternak Babi

\begin{tabular}{|c|c|c|c|c|c|c|c|}
\hline \multirow{3}{*}{ Penyuluhan } & \multicolumn{6}{|c|}{ Sikap Peternak } & \multirow{3}{*}{$\begin{array}{l}\text { Total } \\
\text { Baris }\end{array}$} \\
\hline & \multicolumn{2}{|c|}{ Menerima Inovasi } & \multicolumn{2}{|c|}{$\begin{array}{c}\text { Cukup } \\
\text { Menerima }\end{array}$} & \multicolumn{2}{|c|}{ Kurang Menerima } & \\
\hline & $\left(o_{i}\right)$ & $\left(e_{i}\right)$ & $\left(o_{i}\right)$ & $\left(e_{i}\right)$ & $\left(o_{i}\right)$ & $\left(e_{i}\right)$ & \\
\hline Efektif & 25 & 21.75 & 3 & 4.5 & 2 & 3.75 & 30 \\
\hline Cukup Efektif & 3 & 4.35 & 2 & 0.9 & 1 & 0.75 & 6 \\
\hline Kurang Efektif & 1 & 2.9 & 1 & 0.6 & 2 & 0.5 & 4 \\
\hline Total Kolom & 29 & & 6 & & 5 & & 40 \\
\hline
\end{tabular}


Tabel 8. Uji Analisis Chi-Square Pengaruh Penyuluhan Pada Sikap Peternak Babi.

\begin{tabular}{lccccc}
\hline $\begin{array}{l}\text { Penyuluhan/ } \\
\text { Sikap }\end{array}$ & $o_{i}$ & $e_{i}$ & $\left(o_{i}-e_{i}\right)$ & $\left(o_{i}-e_{i}\right)^{2}$ & $\begin{array}{c}\left(o_{i}-e_{i}\right)^{2 /} \\
e_{i}\end{array}$ \\
\hline (E) Menerima Inovasi & 25 & 21.75 & 3.25 & 10.56 & 0.4856 \\
(E) Cukup Menerima & 3 & 4.5 & -1.5 & 2.25 & 0.0500 \\
(E) Tidak Menerima & 2 & 3.75 & -1.75 & 3.06 & 0.8166 \\
(CE) Menerima Inovasi & 3 & 4.35 & -1.35 & 1.82 & 0.4189 \\
(CE) Cukup Menerima & 2 & 0.9 & 1.1 & 1.21 & 1.3444 \\
(CE) Tidak Menerima & 1 & 0.75 & 0.25 & 0.62 & 0.0833 \\
(TE) Menerima Inovasi & 1 & 2.9 & -1.9 & 3.61 & 1.2440 \\
(TE) Cukup Menerima & 1 & 0.6 & 0.4 & 0.16 & 2.6667 \\
(TE) Tidak Menerima & 2 & 0.5 & 1.5 & 2.25 & 4.5000 \\
\hline Jumlah & 40 & & & & 11.6095 \\
\hline
\end{tabular}

nilai Tabel $x^{2} \mathrm{db}=4 ; \alpha=0.05 \rightarrow x^{2}$ tabel

Keterangan :

(E) : Efektif

(CE) : Cukup Efektif

(TE) : Tidak Efektif

Untuk mengetahui adanya pengaruh maka akan dilakukan pengujian kebebasan variabel dengan taraf uji 5\%.

Ukuran tabel kontingensi di atas $=3 \times 3$ (

3 bariss dan 3 kolom )

$\mathrm{db}=(3-1)(3-1)=2 \times 2=4$

$=9.488$

$x^{2}$ hitung $=11.6095$

$x^{2}$ tabel $=9.488$

$x^{2}$ hitung lebih besar dari $x^{2}$ tabel, artinya penyuluhan berpengaruh nyata pada sikap peternak babi. Indrianingsih (2011) mengatakan bahwa sikap terhadap perubahan menggambarkan kesiapan peternak dalam merespon suatu perubahan.

Tabel 9. Nilai Kontingensi Pengaruh Penyuluhan Pada Keterampilan Peternak Babi

\begin{tabular}{|c|c|c|c|c|c|c|c|}
\hline \multirow[b]{2}{*}{ Penyuluhan } & \multicolumn{6}{|c|}{ Keterampilan } & \multirow{2}{*}{$\begin{array}{l}\text { Total } \\
\text { Baris }\end{array}$} \\
\hline & $\left(o_{i}\right)$ & $\begin{array}{l}\text { pil } \\
\qquad\left(e_{i}\right)\end{array}$ & \multicolumn{2}{|c|}{ Cukup Terampil } & $\begin{array}{l}\text { Kurang } \\
\left(o_{i}\right)\end{array}$ & $\begin{array}{r}\text { Terampil } \\
\left(e_{i}\right)\end{array}$ & \\
\hline $\begin{array}{l}\text { Efektif } \\
\text { Cukup }\end{array}$ & 25 & 21.00 & 3 & 5.25 & 2 & 3.75 & 30 \\
\hline $\begin{array}{l}\text { Efektif } \\
\text { Kurang }\end{array}$ & 2 & 4.9 & 3 & 1.22 & 2 & 0.87 & 7 \\
\hline Efektif & 1 & 2.1 & 1 & 0.52 & 1 & 0.5 & 3 \\
\hline Total Kolom & 28 & & 7 & & 5 & & $=40$ \\
\hline
\end{tabular}


Tabel 10. Uji Analisis Chi-Square Pengaruh Penyuluhan Pada Keterampilan Peternak Babi

\begin{tabular}{lccccc}
\hline $\begin{array}{l}\text { Penyuluhan/ } \\
\text { Keterampilan }\end{array}$ & $o_{\bar{i}}$ & $e_{\bar{i}}$ & $\left(o_{\bar{i}}-e_{i}\right)$ & $\left(o_{\bar{i}}-e_{i}\right)^{2}$ & $\begin{array}{c}\left(o_{i}-e_{i}\right)^{2} / \\
e_{\bar{i}}\end{array}$ \\
\hline (E) Terampil & 25 & 21.00 & 4.00 & 16.00 & 0.7619 \\
(E) Cukup Terampil & 3 & 5.25 & -2.25 & 5.06 & 0.1265 \\
(E) Tidak Terampil & 2 & 3.75 & -1.75 & 3.62 & 0.8166 \\
(CE) Terampil & 2 & 4.90 & -2.9 & 8.41 & 1.7163 \\
(CE) Cukup Terampil & 3 & 1.22 & 1.78 & 3.16 & 2.5970 \\
(CE) Tidak Terampil & 2 & 0.87 & 1.13 & 1.27 & 1.4677 \\
(TE) Terampil & 1 & 2.1 & -1.7 & 2.89 & 1.3761 \\
(TE) Cukup Terampil & 1 & 0.52 & 0.75 & 0.56 & 1.0817 \\
(TE) Tidak Terampil & 1 & 0.37 & 0.63 & 0.39 & 1.0727 \\
\hline Jumlah & 40 & & & & 11.0165 \\
\hline
\end{tabular}

Keterangan :

(E) : Efektif

(CE) : Cukup Efektif

(TE) : Tidak Efektif

Untuk mengetahui adanya pengaruh maka akan dilakukan pengujian kebebasan variabel dengan taraf uji 5\%.

Ukuran tabel kontingensi di atas $=3 \times 3$ ( 3 baris dan 3 kolom)

$\mathrm{db}=(3-1)(3-1)=2 \times 2=4$

nilai Tabel $x^{2} \mathrm{db}=4 ; \alpha=0.05 \rightarrow x^{2}$ tabel

$=9.488, x^{2}$ hitung $=11.0165, x^{2}$ tabel $=$ 9.488

$x^{2}$ hitung lebih besar dari $x^{2}$ tabel, artinya variabel penyuluhan berpengaruh nyata pada keterampilan peternak babi. Peternak yang terampil mampu merubah dirinya melalui komunikasi dengan orang lain untuk menentukan bagaimana kegiatan usaha akan menguntungkan (Levis, 1996).

Hasil peneltian ini sesuai dengan Yunasaf (2012), yang menyatakan bahwa penyuluhan sebagai bagian dari system pendidikan yang sifatnya non formal akan memberikan penguatan kepada para peternak, karena peternak akan memungkinkan untuk berubah perilakunya kearah yang diharapkan, sehingga pengetahuannya akan lebih meningkat, sikapnya akan lebih positif terhadap perubahan dan penerimaan inovasi, dan akan lebih terampil di dalam melaksanakan usaha ternaknya.

\section{KESIMPULAN}

Penyuluhan memberikan pengaruh kepada peternak babi dari sisi peningkatkan pengetahuan, menimbulkan sikap positif terhadap usaha ternak babi serta meningkatkan keterampilan peternak dalam menjalankan usaha peternakan babi di Kecamatan Kawangkoan. 


\section{DAFTAR PUSTAKA}

Amanah, Siti. 2007. Makna penyuluhan dan transformasi perilaku manusia. Jurnal Penyuluhan.Institut Pertanian Bogor.3(1):64-67.

Asngari P.S. 2001. Peranan Agen Pembaharuan/Penyuluh dalam Usaha Memberdayakan (empowerment) Sumberdaya Manusia Pengelola Agrobisnis. Orasi Ilmiah Guru Besar Tetap Ilmu Sosial Ekonomi. Fakultas Peternakan, Institut Pertanian Bogor. 15 September 2001.

Anisa. N. K, A. Abdullah, dan S. N. Kasim. 2016. Pengaruh pengetahuan dan motivasi peternak sapi potong terhadap adopsi teknologi biogas di Desa Bumiayu Kecamatan Wonomulyo Kabupaten Polman. Jurnal Ilmu dan Industri Peternakan,. 3(2):78-79.

Anwas O. M. 2013. Pengaruh pendidikan formal, pelatihan, dan intensitas pertemuan terhadap kompetensi penyuluh pertanian. Jurnal Pendidikan dan Kebudayaan. 19(1): 50-62.

Ediset dan A. Anas. 2013. Peranan penyuluh dalam penerapan paket teknologi pada usaha peternakan kerbau, studi kasus pada kelompok ternak "kerbau antrada" Kecamatan Kota Baru Kabupaten Dharmasraya. Jurnal Peternakan Indonesia. 15(1):1907-1760.

Gobel A., A. A. Sajow, S. O. B Lombogia dan G. D. Lenzun. 2018. Peran pemyuluhan terhadap pemanfaatan limbah perusahaan peternakan ayam ras di Desa Tateli Kecamatan Mondolang Kabupaten Minahasa. Universitas Sam Ratulangi. Jurnal Zootek 38(1): 192-199.
Indrianingsih S. K. 2011. Pengaruh penyuluhan terhadap keputusan petani dalam adopsi inovasi teknologi usaha tani terpadu. Jurnal Agro Ekonomi. 29 (1): 11-12.

Levis, L. R. 1996. Komunikasi Penyuluhan Pedesaan Citra Aditya Bandung.

Priyono, M. I. Shiddieqy, D. Widiyantono, dan Zulfanita. 2015. Hubungan kausal antara tingkat penguasaan teknologi, dukungan kelembagaan, dan peran penyuluhan terhadap adopsi integrasi ternak. Jurnall Informatika Pertanian. 24(2):141148.

Ratnada, Made dan Yusuf. 2003. Perilaku petani dalam konservasi lahan pada sistem usaha pertanian padi sawah irigasi di Imogiri Bantul. Jurnal Pengkajian dan Pengembangan Teknologi Pertanian. (6)1: 29-39. .

Rintjap, A. K., J. Lainawa dan T. Lumy. 2017. Penyuluhan BP3K terhadap perkembangan usaha pemeliharaan ayam kampong di Kecamatan Pineleng Kabupaten Minahasa. Prosiding, Seminar nasional berkelanjutan berbasis peternakan di Indonesia. Universitas Sam Ratulangi, Manado, 23 Maret. P.108-110.

Tsalitsa. A. dan Y. Rachmansyah. 2016. Analisis pengaruh literasi keuangan dan faktor demografi terhadap pengambilan kredit pada PT. Columbia Cabang Kudus. Program Studi Manajemen STIE Bank BPD Jateng. Jurnal Media Ekonomi dan Manajemen 31(1): 6-7.

Tulong, M. J., A. A. Sajow, dan G.D. Lenzun. 2019. Partisipasi peternak sapi dalam penyuluhan di Desa Tondegesan Satu Kecamatan Kawangkoan Kabupaten Minahasa. 
Universitas Sam Ratulangi Manado. Jurnal Zootek 39(2): 184-193.

Yulida. R. Kausar dan L. Marjelita. 2012. Dampak kegiatan penyuluhan terhadap perubahan perilaku petani sayuran di Kota Pekanbaru. Indonesian Journal of Agricultural Economics.3(1):37-5 
